\title{
PERSPECTIVAS PARA UMA EDUCAÇÃO INCLUSIVA: UM OLHAR PONTUAL POR MEIO DA UTILIZAÇÃO DE RECURSOS TANGÍVEIS E INTANGÍVEIS
}

Joaquim Augusto Souza de Menezes

\section{Resumo}

Este estudo é direcionado a linha do tempo sobre Educação Inclusiva, conforme a Legislação Educacional Brasileira. É narrado pela subjetividade da legislação, dando destaque a trajetória do conjunto das leis, decretos, portarias, resoluções, aviso circular e documentação internacional. Desta maneira, o elo percorrido se dá em nível sistêmico e holístico, com vistas a compreender quais as perspectivas para uma Educação Inclusiva por meio do olhar pontual na utilização de recursos tangíveis e intangíveis.

\section{Palavras-chave:}

Linha do Tempo; Educação Inclusiva; Legislação Educacional Brasileira.

\section{I - INTRODUÇÃO}

O foco desse estudo é direcionado a Educação Inclusiva, mas por meio do olhar pontual acerca da legislação brasileira. É decorrente da disciplina Ensino e Aprendizagem em Artes, ministrada pelos Professores Doutores Áureo Deo de Freitas Junior e Joel Cardoso da Silva, do Programa de PósGraduação em Artes do Instituto de Ciências da Arte da Universidade Federal do Pará, tem como cenário narrativo o segundo semestre de dois mil e dezessete, especificamente o laboratório/ sala de aula 2 do espaço físico do PPGARTES, e está organizado em pilares, que mantêm entre si grande interlocução, com vistas a viabilizar uma adequada compreensão dialética - método de diálogo cujo foco é a contraposição e contradição de ideias que levam a outras ideias -.

Desta maneira, o autor trás para essa dialética, logo de início a Lei de Diretrizes e Bases da Educação Nacional, Lei n. 9.394, de 20 de dezembro de 1996, que em seu primeiro artigo diz que a educação deve abranger os processos
Abstract

This study is directed to the time line on Inclusive Education, according to the Brazilian Educational Legislation. It is narrated by the subjectivity of the legislation, highlighting the trajectory of the set of laws, decrees, ordinances, resolutions, circular notice and international documentation. In this way, the link is taken at a systemic and holistic level, in order to understand the perspectives for an Inclusive Education through the point of view of the use of tangible and intangible resources.

Keywords:

Timeline; Inclusive Education; Brazilian Legislation.

formativos que se desenvolvem na vida familiar, na convivência humana, no trabalho, nas instituições de ensino e pesquisa, nos movimentos sociais e organizações da sociedade civil e nas manifestações culturais.

Esses processos são direcionados a disciplinar a educação no âmbito da escola, com a finalidade de desenvolver, predominantemente, o ensino, quer em Instituição Pública e/ou Particular. Por outro lado, a educação escolar deverá vincularse ao mundo do trabalho e à prática social.

Certo? Talvez? Não. Isto é, considerando a realidade do nosso mundo chamado Brasil, e considerando o que preceitua a legislação educacional, há uma grande lacuna sobre o que seria o ideal do real, aqui chamado de "intenções", ou melhor, "diretrizes educacionais", e mais ainda, se estas "intenções" ou "diretrizes educacionais" já são bastante incipientes nas ações "regulares". Imaginemos como se dá no mundo real das crianças, jovens e adultos que necessitam e estão sobre o cuidado da Educação Inclusiva. Imaginou? Qual a sua reflexão sobre a questão ora posta? 


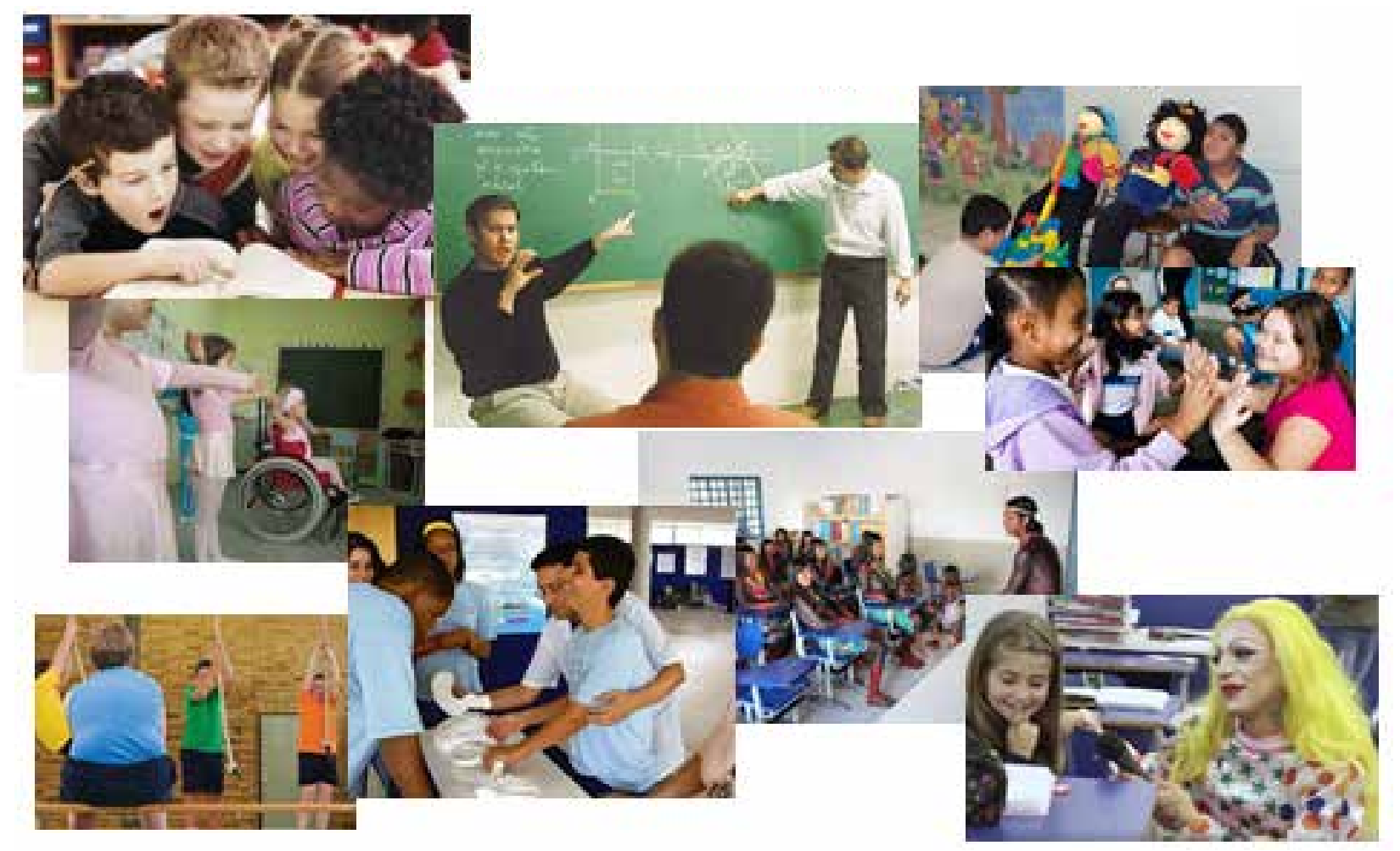

Figura 1 - Fonte: http://educacaoinclusivaemfoco.com.br/os-beneficios-daescola-inclusiva/ (2017).

Nesse sentido, o estudo se propõe a discutir a tipologia entre o que consta na proposta da $L e i / L D B / N^{\circ}$ 9394/96, com a realidade, visando compreender a distorção entre o elo da "ficção" e a realidade existente nos processos da Educação Inclusiva, objetivando fortalecer o que rege o capítulo V, artigo 58, da Lei das Diretrizes e Bases Nacionais, que classifica educação especial "como modalidade de educação escolar, oferecida, preferencialmente, na rede regular de ensino, para educando portadores de necessidades especiais". E em seu $\S 1^{\circ}$, diz: "haverá, quando necessário, serviços de apoio especializado, na escola regular, para atender às peculiaridades da clientela de educação especial", por este motivo, o não cumprimento da Lei, justifica-se a intensão desse estudo.

\section{II - EDUCAÇÃO INCLUSIVA: APORTE PARA A LEGISLAÇÃO BRASILEIRA}

Há quase trinta anos, mais precisamente em 16 de abril de 1989, chegou ao mundo minha primeira sobrinha, Carolina, concebida por meio de uma linda historia de amor. Seus pais se prepararam para este momento, lembro-me como se fosse hoje, cada detalhe destinado a sua chegada, que belo. Todavia, e segundo a lei maior do Arquiteto do Universo, a escritura sagrada, o sopro da vida é de competência Dele, e é Ele que escolhe cada casal para receber seus filhos, isto é, para aqueles que acreditam na existência do Pai, do Filho e do Espírito Santo.

Carolina chegou ao final da manhã de domingo, na maternidade do Hospital Adventista de Belém, e nesta manhã fui levado a Basílica de Nossa Senhora de Nazaré, a orar pela sua chegada, essa atitude ocorreu somente em seu nascimento, e o motivo não sabia, mas hoje sei o porquê, fui a terceira pessoa a saber de sua chegada, mas ao receber a noticia do seu nascimento percebi que havia na voz da minha mulher um aperto de choro, foi quando Ela falou: "Augusto nossa Carolina é especial, é portadora de síndrome de down ${ }^{1 "}$, naquele exta momento tudo ficou escuro, porém sabia que passaria, tinha que saber o porquê dessa situação, lembro-me que falei: "depois Eu vou até aí".

Então, pedi força e direcionamento à mãezinha de Nazaré que me conduziu, e fui direcionado a Associação de Pais e Amigos dos Excepcionais de Belém (APAE Belém) ${ }^{2}$, e chegando lá tive meu 


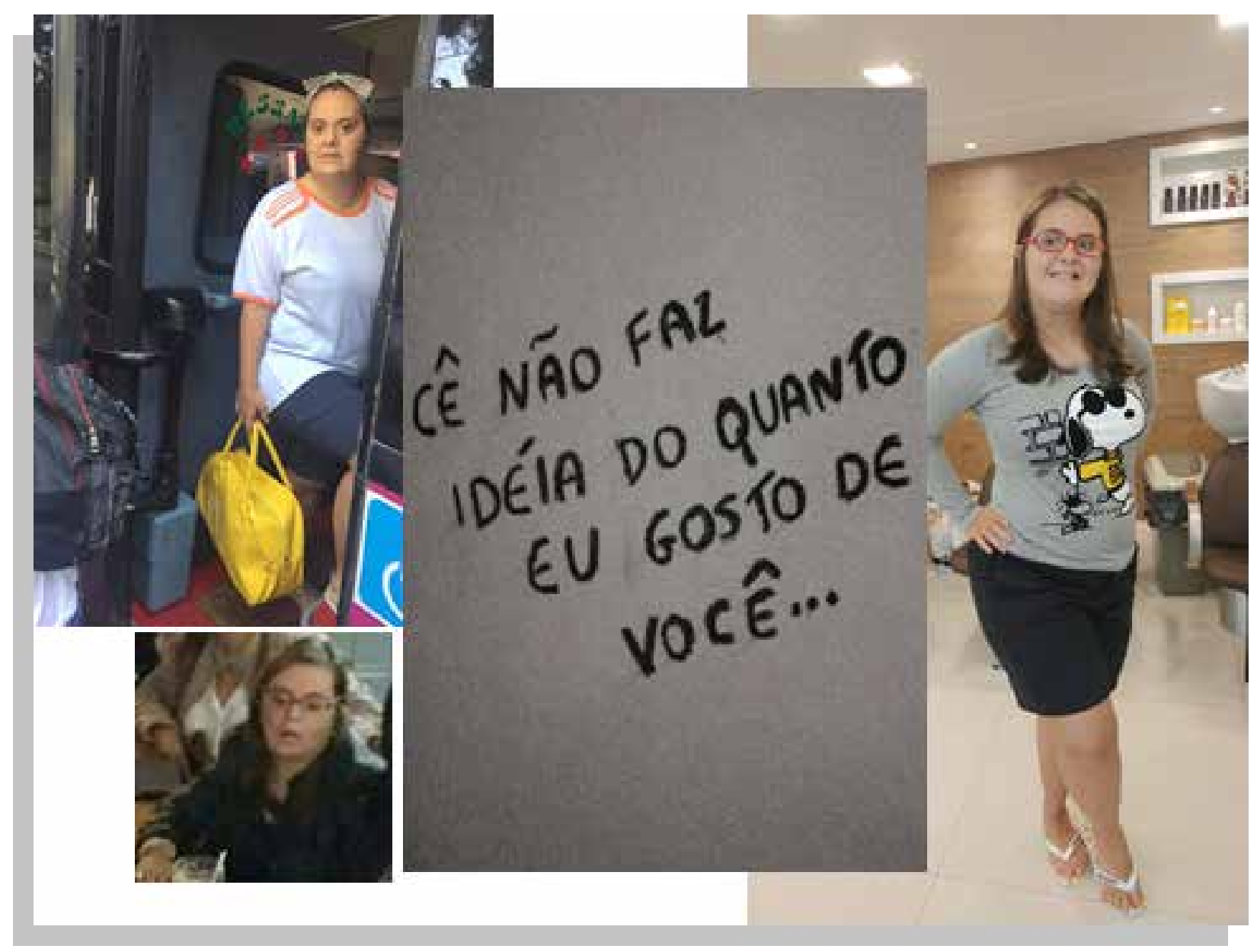

Figura 2 - Fonte: Acervo fotográfico do autor (2017).

primeiro contato com o mundo lindo, criativo, harmônico, feliz, e acima de tudo gratificante no sentido do amor pelo amor, e nesse mesmo dia nasceu uma nova vida para mim, para os meus e para muitos que Eu não sabia que existiam, mas que passaram a existir após o nascimento de minha linda e amada Carolina, pois me tornei Diretor Social desta associação, e hoje sem qualquer tipologia heroína posso dizer que minha Carolina, Carol, é o mais belo anjo enviado por Deus ao seio de seus familiares.

Carol, hoje é uma mulher bela, atuando nas áreas das artes, quer por meio de suas gravuras; pinturas; reciclagem para dar vida ao novo; faz parte de grupos de dança e teatro; na música tocar flauta e cantar em coro; mais foi culinária que Ela se encontrou e tem a sua própria marca: "doces finos Carolina".

Em 2018, recebi mais uma notícia, todavia minha reação foi simples e direcionada a mãe da Carol: "você é magnifica e abençoada por Deus", minha Carol foi diagnostica com Transtorno do Espectro do Autismo ${ }^{4}$, e talvez, você não esteja entendendo minhas palavras a minha cunhada, explico, "somente o amor de mãe é capaz de viver tão feliz, como Ela vive: com a Carol, seu marido, sua outra filha e filho".

Não havia como não realizar essa pesquisa, que levou a consolidar a escolha desse artigo, pela tipologia vivenciada, e em constante vivencia, com a minha linda e amada Carol, e expressa por meio da figura 02, cujo título: "Um Ser Mais que Especial - minha amada e linda Carol".

Nesse sentido, o foco desse levantamento imaterial é central a congregar em um único apontamento todo o acervo legislativo destinado ao trato acerca da Educação Inclusiva, mais por meio da subjetividade entre "sociedade versus valores diversos; instituições; e relação versus com e em pessoas, portadoras e/ou não de alguma síndrome, entretanto com TODOS QUE NECESSITAM DO OLHAR INCLUSIVO NO SEIO DA EDUCAÇÃO". 


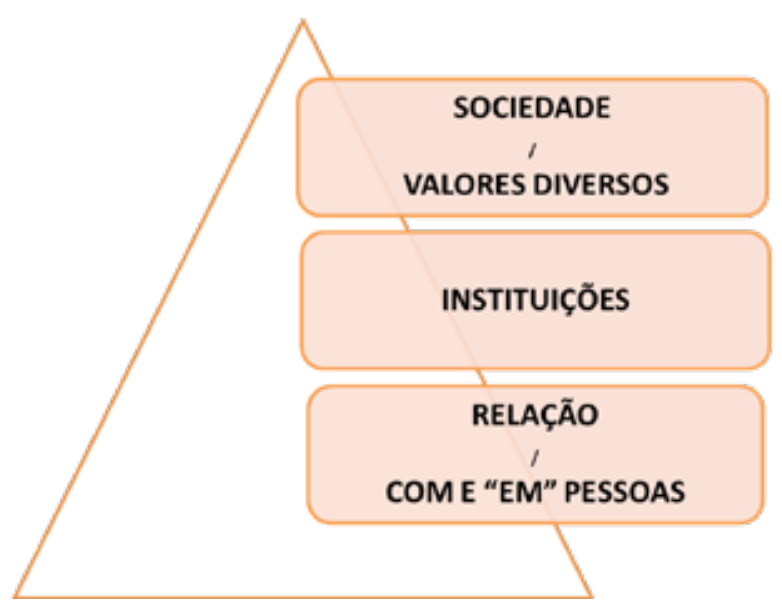

Figura 3 - "Pirâmide dos Versus", uma ação de criação do autor desse artigo (fonte/2017).

Nesse sentido e visando consolidar essa subjetividade, ocorre à criação da pirâmide abaixo, que consolida em um mesmo espaço, porém em três estágios a correção entre a Sociedade, que somos todos nós, mas na tipologia de cada um de nós, ilustrada esta visão por meio da figura 03, intitulada: "Pirâmide dos Versus", uma ação de criação do autor desse artigo (fonte/2017).

Sendo assim, não buscamos esmiuçar cada instrumento normativo, e sim correlacionar este versus sua destinação, considerando que já foi apreciado por quem o direito de aprecialos, e posteriormente, torna-los instrumento normatizadores e legais, entretanto, dentro dos princípios fundamentais do Estado Democrático de Direito ${ }^{4}$, pois para existir este é necessário que os instrumentos estejam de acordo com a CONSTITUIÇÃO FEDERAL, ficando a interpretação de cada instrumental, ora mencionado, a quem necessitar utiliza-lo, mas na especificidade da sua própria necessidade, pois o acervo sobre Educação Inclusiva é parte integrante do instrumento maior a LDB n 9394/96, contida na lei maior, a Carta Magna de um País.

Contudo, é relevante citar que a primeira LDB, a de 1961, insere em seu texto constitucional a especificidade em relação ao lidar com as pessoas com "deficiência", a qual é destinada - TÍTULO X - Da Educação dos Excepcionais (BRASIL, 1961, p. 16) ${ }^{5}$ :

Art. 88. A educação de excepcionais deve, no que for possível, enquadrar-se no sistema geral de educação, a fim de integrá-los na comunidade.
Art. 89. Toda iniciativa privada considerada eficiente pelos conselhos estaduais de educação, e relativa à educação dos excepcionais, receberá dos poderes públicos tratamento especial mediante bolsas de estudo, empréstimos e subvenções.

Para esse atendimento, tornou-se dever do Estado o fornecimento de serviços de apoio a esses alunos dentro das escolas regulares ou serviço especializado em ambiente externo a essas escolas quando essa participação não for possível, contudo mantendo como objetivo principal a ampliação do atendimento dessa população dentro das escolas regulares (BRASIL, 1996, p. 21):

$\S 1^{\circ}$ Haverá, quando necessário, serviços de apoio
especializado na escola regular para atender as
peculiaridades da clientela de educação especial.

$\S 2^{\circ} \mathrm{O}$ atendimento educacional será feito em classes, escolas ou serviços especializados, sempre que, em função das condições específicas dos alunos, não for possível a sua integração nas classes comuns de ensino regular.

A educação especial, hoje, educação inclusiva, teve seu conceito transformado durante as elaborações das diferentes versões das Leis de Diretrizes e Bases, suprindo a primeira ideia de uma educação em ambiente e de forma diferentes e separados dos demais, por uma nova compreensão na qual ocorre uma adaptação de todo o sistema escolar para atender esse aluno dentro das escolas regulares.

Por outro lado, o entendimento sobre o conceito inicial, não estar fechado, e sim em constante construção, visto que a realidade de hoje é decorrente do ontem, e as tempestividades do hoje será fruto migratório para o amanhã.

A Constituição da República Federativa do Brasil de 1988, promulgada em 5 de outubro de 1988, em seu artigo $n^{\circ}$. 205, trás o seguinte entendimento sobre a educação:

\footnotetext{
“A educação, direito de todos e dever do Estado e da família, será promovida e incentivada com a colaboração da sociedade, visando ao pleno desenvolvimento da pessoa, seu preparo para o exercício da cidadania e sua qualificação para o trabalho"6.
}

Por sua vez, o artigo n²06, diz que o ensino será ministrado com base no princípio da igualdade de condições para o acesso e permanência na escola. E o artigo $n^{\circ} 208$, enfatiza que o dever do Estado com a Educação será efetivado 
mediante a garantia do atendimento educacional especializado aos portadores de deficiência, preferencialmente na rede regular de ensino, sendo o atendimento em creche e pré-escola às crianças de 0 a 5 anos de idade.

0 artigo $n^{\circ}$ 213, diz respeito aos recursos públicos, e serão destinados às escolas, podendo ser dirigidos a escolas comunitárias, confessionais ou filantrópicas, definidas em lei, com a finalidade de comprovar a finalidade não lucrativa, e apliquem seus excedentes financeiros em educação. Estes são os entendimentos legais inseridos na Lei maior do país, e deve envolver em nosso ponto de vista a tipologia: SOCIEDADE / VALORES DIVERSOS / INSTITUIÇÕES / RELAÇÃO /COM E "EM" PESSOAS, visando no mínimo a internalização deste artigo.

Por outro lado, a Lei $n^{\circ}$ 9.394/96, em seu capítulo $V$, direciona um cuidar especificamente à Educação Especial. Em nosso ponto de vista o artigo 58, enfatiza que a educação especial, no tocante a 9394/96, é uma modalidade de educação escolar, oferecida preferencialmente na rede regular de ensino, para educandos portadores de necessidades especiais.

No parágrafo primeiro do referido artigo, digo, art. 58/CF/88, é sustentado que haverá, quando necessário, serviços de apoio especializado, na escola regular, para atender as peculiaridades da clientela de educação especial, por sua vez, o atendimento educacional será feito em classes, escolas ou serviços especializados, sempre que, em função das condições específicas dos alunos, caso não for possível a sua integração nas classes comuns do ensino regular. Este entendimento é contemplado no parágrafo $2 \%$ art. 58/CF/88. E com relação a oferta da educação especial é dever constitucional do Estado, e tem seu início na faixa etária de zero a seis anos, durante a educação infantil, conforme o parágrafo 3\%art. 58/CF/88.

Os sistemas de ensino assegurarão aos educandos com necessidades especiais as seguintes condições, relacionadas nos incisos, abaixo do artigo 59, da Lei $n^{\circ}$ 9.394/96:

- I - currículos, métodos, técnicas, recursos educativos e organizações específicas, para atender às suas necessidades;
- II - terminalidade específica para aqueles que não puderem atingir o nível exigido para a conclusão do ensino fundamental, em virtude de suas deficiências, e aceleração para concluir em menor tempo o programa escolar para os superdotados;

- III-professores com especialização adequada em nível médio ou superior, para atendimento especializado, bem como professores do ensino regular capacitados para a integração desses educandos nas classes comuns;

- IV - educação especial para o trabalho, visando a sua efetiva integração na vida em sociedade, inclusive condições adequadas para os que não revelarem capacidade de inserção no trabalho competitivo, mediante articulação com os órgãos oficiais afins, bem como para aqueles que apresentam uma habilidade superior nas áreas artística, intelectual ou psicomotora;

- V - acesso igualitário aos benefícios dos programas sociais suplementares disponíveis para o respectivo nível do ensino regular.

Os órgãos normativos dos sistemas de ensino estabelecerão critérios de caracterização das instituições privadas sem fins lucrativos, especializadas e com atuação exclusiva em educação especial, para fins de apoio técnico e financeiro pelo Poder Público. Sendo assim, cabe ao Poder Público adotar, como alternativa preferencial, a ampliação do atendimento aos educandos com necessidades especiais na própria Rede Pública Regular de Ensino, independentemente do apoio às instituições previstas, é o que referenda o artigo 60, em seu parágrafo único.

Outro aspecto a ser considerado para a Educação Inclusiva na visão deste autor, diz respeito à $L e i$ $n^{\circ}$. 8.069, de 13 de julho de 1990, que dispõe sobre o Estatuto da Criança e do Adolescente, e em seu capítulo IV, se refere ao Direito à Educação, à Cultura, ao Esporte e ao Lazer, porém trataremos, neste estudo, somente ao aspecto da Educação.

Desta forma, o artigo 53 sustenta que a criança e o adolescente têm direito à educação, visando ao pleno desenvolvimento de sua pessoa, preparo 
para o exercício da cidadania e qualificação para o trabalho, assegurando-lhes: I - igualdade de condições para o acesso e permanência na escola; II - direito de ser respeitado por seus educadores; III - direito de contestar critérios avaliativos, podendo recorrer às instâncias escolares superiores; IV direito de organização e participação em entidades estudantis; V - acesso à escola pública e gratuita próxima de sua residência.

Então, é direito dos pais ou responsáveis ter ciência do processo pedagógico, bem como, participar da definição das propostas educacionais, conforme o parágrafo único do referido artigo. E afirma por meio do artigo 54, que é dever do Estado assegurar à criança e ao adolescente os direitos:

- I - ensino fundamental, obrigatório e gratuito, inclusive para os que a ele não tiveram acesso na idade própria; II - progressiva extensão da obrigatoriedade e gratuidade ao ensino médio;

- $\quad$ III - atendimento educacional especializado aos portadores de deficiência, preferencialmente na rede regular de ensino; IV - atendimento em creche e pré-escola às crianças de zero a seis anos de idade; IV - atendimento em creche e pré-escola às crianças de zero a cinco anos de idade - nova redação advinda pela Lei $n^{\circ}$. 13.306/2016; V - acesso aos níveis mais elevados do ensino, da pesquisa e da criação artística, segundo a capacidade de cada um; VI - oferta de ensino noturno regular, adequado às condições do adolescente trabalhador; VII atendimento no ensino fundamental, através de programas suplementares de material didático-escolar, transporte, alimentação e assistência à saúde.

Os parágrafos $1^{\circ}, 2^{\circ}$ e $3^{\circ}$, referem-se, respectivamente: o acesso ao ensino é obrigatório, gratuito, e é direito público subjetivo; o não oferecimento do ensino obrigatório pelo Poder Público ou sua oferta irregular importa responsabilidade da autoridade competente, e, compete ao Poder Público recensear os educandos no ensino fundamental, fazer-lhes a chamada e zelar, junto aos pais ou responsável, pela frequência à escola.

Os artigos de $\mathrm{n}^{\circ} \mathrm{s}$. 55, 56, 57 e 58, abordam a responsabilidade dos pais com a efetivação da matrícula escolar. E salienta que é de competência dos dirigentes de estabelecimentos de Ensino Fundamental comunicar ao Conselho Tutelar as ocorrências de maus-tratos, de reiteração de faltas injustificadas, de evasão escolar, dos elevados níveis de repetência, e por fim esgotados os recursos escolares, cabe ao Poder Público estimular pesquisas, experiências e novas propostas relativas a calendário, seriação, currículo, metodologia, didática e avaliação, visando à inserção das crianças e dos adolescentes excluídos do Ensino Fundamental. É obrigatório que no processo educacional exista o respeito aos valores culturais, artísticos, históricos adequados ao contexto social das crianças e dos adolescentes, garantindo a estes, o direito a liberdade da criação e o acesso às fontes de cultura.

A Lei no. 10.098, de 19 de dezembro de 2000, estabelece normas gerais e critérios básicos para a promoção da acessibilidade das pessoas portadoras de deficiência ou com mobilidade reduzida. Todavia, é bem evidente, e de maneira incipiente, a empregabilidade desta normalização em nosso ponto de vista.

As ações voltadas para a linguagem de sinais, prevista na Lei $n^{0} 10.436$, de 24 de abril de 2002, é reconhecida como meio legal de comunicação e expressão da Língua Brasileira de Sinais (Libras), e os recursos de expressão a ela associados. o sistema educacional, Federal, Estadual, Municipal e do Distrito Federal deve garantir a inclusão nos cursos de formação de Educação Especial, de Fonoaudiologia, e de Magistério, em seus níveis Médio e Superior, o ensino da Língua Brasileira de Sinais, como parte integrante dos Parâmetros Curriculares Nacionais - PCN's. A Língua Brasileira de Sinais, não poderá substituir a modalidade escrita da língua portuguesa.

A preocupação com as pessoas que apresentam necessidades especiais (deficiência) na Lei $n^{\circ} 7.853$ de 24 de outubro de 1989refere que o procedimento de integração social, é de responsabilidade da Coordenadoria para a Integração da Pessoa Portadora de Deficiência - CORDE, e institui a tutela jurisdicional de interesses coletivos ou difusos dessas pessoas, disciplinando a atuação do Ministério Público no que define, como crimes, e outros entendimentos, citando que cabe ao 
Poder Público e seus órgãos, assegurar às pessoas portadoras de deficiência o pleno exercício de seus direitos básicos, inclusive dos direitos à educação, à saúde, ao trabalho, ao lazer, à previdência social, ao amparo à infância e à maternidade, e de outros que, decorrentes da Constituição e das Leis Especificas, venham propiciar seu bem-estar pessoal, social e econômico.

Os órgãos e Entidades da Administração Direta e Indireta devem dispensar, no âmbito de sua competência e finalidade, aos assuntos objetos dessa Lei, tratamento prioritário e adequado, tendente a viabilizar, sem prejuízo de outras, as seguintes medidas:

I - Na área da educação:

- a) a inclusão, no sistema educacional, da Educação Especial como modalidade educativa que abranja a educação precoce, a pré-escolar, as de $1^{\circ}$ e $2^{\circ}$ graus, a supletiva, a habilitação e reabilitação profissionais, com currículos, etapas e exigências de diplomação própria;

- b) o oferecimento obrigatório de programas de Educação Especial em estabelecimentos públicos de ensino;

- c) a oferta, obrigatória e gratuita, da Educação Especial em estabelecimentos públicos de ensino;

- d) o oferecimento obrigatório de programas de Educação Especial em nível pré-escolar e escolar, em unidades hospitalares e congêneres nas quais estejam internados, por prazo igual ou superior a um (um) ano, educandos portadores de deficiência;

- e) o acesso de alunos portadores de deficiência aos benefícios conferidos aos demais educandos, inclusive material escolar, merenda escolar e bolsa de estudo;

- f) a matrícula compulsória em cursos regulares de estabelecimentos públicos e particulares de pessoas portadoras de deficiência capazes de se integrarem ao sistema regular de ensino.

Já a legislação de $n^{\circ} 8.859$ de 23 de março de 1994, trás uma nova redação ao dispositivo da Lei $n^{\circ}$ 6.494, de 7 de dezembro de 1977, estendendo aos alunos de Ensino Especial o direito à participação em atividades de Estágio, vejamos a transcrição do artigo $1^{\circ}$ da referida lei:

Art. $1^{\circ}$ - As pessoas jurídicas de Direito Privado, os órgãos de Administração Pública e as Instituições de Ensino podem aceitar, como estagiários, os alunos regularmente matriculados em cursos vinculados ao ensino público e particular. Desta forma, os alunos a que se refere o "caput" deste artigo devem, comprovadamente, estar frequentando cursos de nível superior, profissionalizante de $2^{\circ} \mathrm{grau}$, ou escolas de educação especial, contemplado no parágrafo primeiro do referido artigo/lei.

Além desse conjunto de normatização e normalização em contexto de LEl, há outros instrumentos disciplinares que corroboram com a aplicabilidade dos processos verticalizados e horizontalizados acerca do olhar inclusivista para a Educação Especial, e estão contemplados pelos DECRETOS. Mas qual o entendimento sobre decreto?

Para Meirelles, em sentido próprio e restrito, decretos são: "atos administrativos da competência exclusiva dos chefes do Executivo, destinados a prover situações gerais ou individuais, abstratamente previstas de modo expresso, explícito pela legislação". (MEIRELLES, 2003, p. 34).

São Decretados sobre o olhar inclusivista emanados pelo Poder Executivo Federal:

- O Decreto $N^{\circ} 186 / 08$, aprova o texto da Convenção sobre os Direitos das Pessoas com Deficiência e de seu Protocolo Facultativo, assinados em Nova lorque, em 30 de março de 2007. Este ato foi aprovado pelo Senador Garibaldi Alves Filho, Presidente do Senado Federal, e refere-se ao disposto no artigo $5^{\circ}$, $\S 3^{\circ}$, da Constituição Federal/1988, nos termos do artigo 48, inciso XXVIII, do Regimento Interno, enfatiza que:

- "Art. $1^{\circ}$ Fica aprovado, nos termos do $\S 3^{\circ}$ do art. $5^{\circ}$ da Constituição Federal, o texto da Convenção sobre os Direitos das Pessoas com Deficiência e de seu Protocolo Facultativo, assinados em Nova Iorque, em 30 de março de 2007". O parágrafo único passa a ter a seguinte redação: “Ficam sujeitos à aprovação do Congresso Nacional quaisquer atos que alterem a referida Convenção e seu Protocolo Facultativo, bem como quaisquer outros ajustes complementares que, nos termos do 
inciso I do caput do art. 49 da Constituição Federal, acarretem encargos ou compromissos gravosos ao patrimônio nacional".

- Por sua vez, o Decreto $N^{0}$ 6.949/2009, promulga a Convenção Internacional sobre os Direitos das Pessoas com Deficiência e seu Protocolo Facultativo, assinados em Nova York, em 30 de março de 2007, dar evidencia a estes direitos por meio dos artigos $1^{\circ}$ e $2^{\circ}$, transcritos abaixo:

- $\quad$ Art. $1^{\circ}-\mathrm{A}$ Convenção sobre os Direitos das Pessoas com Deficiência e seu Protocolo Facultativo, apensos por cópia ao presente Decreto, serão executados e cumpridos tão inteiramente como neles se contém.

- $\quad$ rt. $2^{\circ}$ - São sujeitos à aprovação do Congresso Nacional quaisquer atos que possam resultar em revisão dos referidos diplomas internacionais ou que acarretem encargos ou compromissos gravosos ao patrimônio nacional, nos termos do art. 49, inciso I, da Constituição.

- Já o Decreto $N^{0}$ 6.094/07, dispõe sobre a implementação do Plano de Metas Compromisso Todos pela Educação, pela União Federal, em regime de colaboração com Municípios, Distrito Federal e Estados, e a participação das famílias e da comunidade, mediante programas e ações de assistência técnica e financeira, visando a mobilização social pela melhoria da qualidade da educação básica.

- A preocupação com o acompanhamento das diretrizes de governo é vista pelo Decreto $N^{0}$ 6.215/07, quando institucionaliza 0 Comitê Gestor de Políticas de Inclusão das Pessoas com Deficiência - CGPD. Dispõe sobre a implementação do Plano de Metas Compromisso Todos pela Educação, e evidencia o Estabelecimento de Compromisso pela Inclusão das Pessoas com Deficiência, com vistas à implementação de ações de inclusão das pessoas com deficiência, por parte da União Federal, em regime de cooperação com Municípios, Estados e Distrito Federal, institui o Comitê Gestor de Políticas de Inclusão das Pessoas com Deficiência - CGPD, dando as seguintes providências:

- Art. $1^{\circ}$ Fica estabelecido o Compromisso pela Inclusão das Pessoas com Deficiência, com o objetivo de conjugar esforços da União, Estados, Distrito Federal e Municípios em proveito da melhoria das condições para a inclusão das pessoas com deficiência na sociedade brasileira.

- Parágrafo único. Os entes participantes do Compromisso atuarão em colaboração com as organizações dos movimentos sociais, com a comunidade e com as famílias, buscando potencializar os esforços da sociedade brasileira na melhoria das condições para a inclusão das pessoas com deficiência.

- Art. $2^{\circ}$ O Governo Federal, atuando diretamente ou em regime de cooperação com os demais entes federados e entidades que se vincularem ao Compromisso, observará, na formulação e implementação das ações para inclusão das pessoas com deficiência, as seguintes diretrizes.

- I - ampliar a participação das pessoas com deficiência no mercado de trabalho, mediante sua qualificação profissional;

- Il - ampliar o acesso das pessoas com deficiência à política de concessão de órteses e próteses;

- III - garantir o acesso das pessoas com deficiência à habitação acessível;

- IV - tornar as escolas e seu entorno acessíveis, de maneira a possibilitar a plena participação das pessoas com deficiências;

- V - garantir transporte e infraestrutura acessíveis às pessoas com deficiência;

- VI - garantir que as escolas tenham salas de recursos multifuncionais, de maneira a possibilitar o acesso de alunos com deficiência.

- Art. $3^{\circ}$ A vinculação do Município, Estado ou Distrito Federal ao Compromisso pela Inclusão das Pessoas com Deficiência farse-á por meio de termo de adesão voluntária cujos objetivos retratarão as diretrizes estabelecidas neste decreto.

- Parágrafo único. A adesão voluntária de cada ente federativo ao Compromisso gera para si a responsabilidade de priorizar medidas visando à melhoria das condições para a inclusão das pessoas com deficiência em sua esfera de competência.

- Art. $4^{\circ}$ Podem colaborar com o Compromisso, em caráter voluntário, outros entes, públicos e privados, tais como organizações da sociedade civil, fundações, entidades de classe 
empresariais, igrejas e entidades confessionais, famílias, pessoas físicas e jurídicas que se mobilizem para a melhoria das condições de inclusão das pessoas com deficiência.

- Art. 50 Fica instituído o Comitê Gestor de Políticas de Inclusão das Pessoas com Deficiência - CGPD, com o objetivo de promover a articulação dos órgãos e entidades envolvidos na implementação das ações relacionadas à inclusão das pessoas com deficiência, resultantes do Compromisso de que trata o art. 10, assim como de realizar o monitoramento e avaliação dessas ações.

- $\S 1^{\circ}$ O Comitê Gestor será composto pelos seguintes órgãos: I - Secretaria Especial dos Direitos Humanos da Presidência da República, que o coordenará; II - Ministério da Educação; III - Ministério da Saúde; IV - Ministério do Desenvolvimento Social e Combate à Fome; V - Ministério das Cidades; VI - Ministério do Trabalho e Emprego; VII - Ministério do Planejamento, Orçamento e Gestão.

- $\$ 2^{\circ}$ OSecretário Especial dos Direitos Humanos da Presidência da República designará os representantes indicados pelos titulares dos órgãos referidos no $\S 10$ e estabelecerá a forma de atuação e de apresentação de resultados pelo Comitê Gestor.

- $\S 3^{\circ} 0$ apoio administrativo e os meios necessários à execução dos trabalhos do Comitê Gestor serão fornecidos pela Secretaria Especial dos Direitos Humanos da Presidência da República.

- $\S 4^{\circ}$ A participação no Comitê Gestor é de relevante interesse público e não será remunerada.

- O benefício de prestação continuada da assistência social devido à pessoa com deficiência e ao idoso é regulamentado pelo Decreto $N^{\circ} 6.214 / 07$, conforme o teor da Lei $n^{\circ} 8.742$, de 7 de dezembro de 1993, e a $L e i$ $n^{\circ} 10.741$, de $1^{\circ}$ de outubro de 2003 , acresce parágrafo ao art. 162 do Decreto $n^{\circ} 3.048$, de 6 de maio de 1999, e dá outras providências.

- Outro aspecto relevante à Educação Inclusiva é tratado pelo Decreto $N^{0} 6.571 / 08$, que dispõe sobre 0 atendimento educacional especializado, regulamenta o parágrafo único do art. 60 da Lei $^{\circ}$ 9.394, de 20 de dezembro de 1996, e acrescenta dispositivo ao Decreto $n^{\circ}$ 6.253, de 13 de novembro de 2007.
- A necessidade da língua de sinais é contemplada pelo Decreto $N^{\circ} 5.626 / 05$, que regulamenta a Lei $n^{\circ} 10.436$, de 24 de abril de 2002, e reforçando o corpo do art. 18 da Lei $n^{\circ}$ 10.098, de 19 de dezembro de 2000.

- 0 Decreto $n^{\circ}$ 2.208/97 regulamenta o parágrafo $2^{\circ}$ do art. 36 e os arts. 39 a 42 da Lei 9.394, de 20/12/1996, que estabelece as Diretrizes e Bases da Educação Nacional. E correlaciona o teor deste ao Decreto $\mathrm{n}^{02} \mathrm{2.406}$ - 27/11/1997, em seu art. 2. (Centro de Educação Tecnológica), regulamenta a Lei 8948, de 08/12/1994.

- A Política Nacional para a Integração da Pessoa Portadora de Deficiência é consolidada pelo Decreto $N^{\circ} 3.298 / 99$, que regulamenta a Lei $n^{\circ} 7.853$, de 24 de outubro de 1989, a qual dispõe sobre normas de proteção: Art. $1^{\circ}$ A Política Nacional para a Integração da Pessoa Portadora de Deficiência compreende o conjunto de orientações normativas que objetivam assegurar o pleno exercício dos direitos individuais e sociais das pessoas portadoras de deficiência; Art. $2^{\circ}$ Cabe aos órgãos e às entidades do Poder Público assegurar à pessoa portadora de deficiência - pleno exercício de seus direitos básicos, inclusive dos direitos à educação, à saúde, ao trabalho, ao desporto, ao turismo, ao lazer, à previdência social, à assistência social, ao transporte, à edificação pública, à habitação, à cultura, ao amparo à infância e à maternidade, e de outros que, decorrentes da Constituição e das leis, propiciem seu bem-estar pessoal, social e econômico, e Art. $3^{\circ}$ Para os efeitos deste Decreto considera-se: I - deficiência - toda perda ou anormalidade de uma estrutura ou função psicológica, fisiológica ou anatômica que gere incapacidade para o desempenho de atividade, dentro do padrão considerado normal para o ser humano; II - deficiência permanente - aquela que ocorreu ou se estabilizou durante um período de tempo suficiente para não permitir recuperação ou ter probabilidade de que se altere, apesar de novos tratamentos; III - incapacidade - uma redução efetiva e acentuada da capacidade de integração social, com necessidade de equipamentos, adaptações, meios ou recursos especiais para que a pessoa portadora de deficiência possa receber ou transmitir informações necessárias ao seu bem-estar pessoal e ao desempenho de função ou atividade a ser exercida.

- O transporte gratuito é garantido por meio do Decreto $N^{\circ}$ 914/93, institui Política Nacional para a Integração da Pessoa Portadora de 
Deficiência, correlacionando a Lei $n^{\circ} 8.899$, de 29/06/1994, passe livre em transporte interestadual (deficientes).

- O Fundo de Manutenção e Desenvolvimento do Ensino Fundamental e de Valorização do Magistério é tratado pelo Decreto $N^{\circ}$ 2.264/97, que regulamenta a Lei 9.424, De 24/12/1996, em âmbito Nacional.

- O Conselho Nacional dos Direitos da Pessoa Portadora de Deficiência - CONADE, vinculado ao Ministério da Justiça é criado pelo Decreto $N^{\circ} 3.076 / 99$.

- O transporte de pessoas portadoras de deficiência no sistema de transporte coletivo interestadual é institucionalizado por meio do Decreto $N^{\circ}$ 3.691/00, que regulamenta a Lei $n^{\circ} 8.899$, de 29 de junho de 1994, conforme os artigos: Art. $1^{\circ}$ As empresas permissionárias e autorizatárias de transporte interestadual de passageiros reservarão dois assentos de cada veículo, destinado a serviço convencional, para ocupação das pessoas beneficiadas pelo art. $1^{\circ}$ da Lei no 8.899, de 29 de junho de 1994, observado o que dispõem as Leis $n^{\circ} \mathrm{S}$ 7.853 , de 24 de outubro de $1989,8.742$, de 7 de dezembro de 1993, 10.048, de 8 de novembro de 2000, e os Decretos $n^{\circ} \mathrm{S} 1.744$, de 8 de dezembro de 1995, e 3.298, de 20 de dezembro de 1999. Art. $2^{\circ} 0$ Ministro de Estado dos Transportes disciplinará, no prazo de até trinta dias, o disposto neste Decreto.

- As atividades do Conselho Nacional de Combate à Discriminação no âmbito da Federação - é regulamentada - pelo Decreto $N^{\circ} 3.952 / 01$.

- Já o Decreto $N^{\circ}$ 5.296/04, regulamenta as Leis $n^{\circ} \mathrm{s} 10.048$, de 8 de novembro de 2000, que dá prioridade de atendimento às pessoas que especifica, e 10.098, de 19 de dezembro de 2000, que estabelece normas gerais e critérios básicos para a promoção da acessibilidade das pessoas portadoras de deficiência ou com mobilidade reduzida.

- A promulgação da Convenção Interamericana para a Eliminação de Todas as Formas de Discriminação contra as Pessoas
Portadoras de Deficiência é cuidadosamente regulamentada pelo Decreto $N^{\circ} 3.956 / 01$.

Em nível de Portarias, que se interligam as Leis e aos Decretos com a finalidade de regimentar ou dar maior praticidade a aplicabilidade destes instrumentos, teremos:

- A Portaria $n^{\circ}$ 976/06, dispõe sobre os critérios de acessibilidade aos eventos do Ministério da Educação, conforme Decreto 5.296 de 2004.

- A recomendação à inclusão da disciplina "ASPECTOS ÉTICO-POLITICO EDUCACIONAIS DA NORMALIZAÇÃO E INTEGRAÇÃO DA PESSOA PORTADORA DE NECESSIDADES ESPECIAIS", prioritariamente, nos cursos de Pedagogia, Psicologia e em todas as Licenciaturas, é a preocupação da Portaria $n^{\circ} 1.793 / 94$, em seu art. $1^{\circ}$. E no art. $2^{\circ}$ da mesma Portaria, há a Recomendação para a inclusão de conteúdos relativos aos aspectos-Ético-Políticos-Educacionais da Normalização e Integração da Pessoa Portadora de Necessidades Especiais nos cursos do grupo de Ciência da Saúde (Educação Física, Enfermagem, Farmácia, Fisioterapia, Fonoaudiologia, Medicina, Nutrição, Odontologia, Terapia Ocupacional), no Curso de Serviço Social e nos demais cursos superiores, de acordo com as suas especificidades. Por fim, o art. $3^{\circ}$. Recomendar a manutenção e expansão de estudos adicionais, cursos de graduação e de especialização já organizados para as diversas áreas da Educação Especial.

- Já ações de acessibilidade são tratadas por meio da Portaria $n^{\circ} 3.284 / 03$, que dispõe sobre requisitos de acessibilidade de pessoas portadoras de deficiências, para instruir os processos de autorização e de reconhecimento de cursos, e de credenciamento de instituições.

- A criação da Comissão Brasileira do Braille vinculada ao Ministério da Educação / Secretaria de Educação Especial (SEESP), foi instituída pela Portaria $n^{\circ} 319 / 99$, e o Regulamento Interno da Comissão Brasileira do Braille, foi regimentado por meio da Portaria $n^{\circ} 554 / 00$. 
- O Ministério do Planejamento, Orçamento e Gestão, por meio da Portaria $n^{\circ} 8 / 01$, resolve:

- Art. $1^{\circ}$ Os órgãos e entidades da Administração Pública Federal direta, autárquica e fundacional que tenham condições de proporcionar experiência prática na linha de formação, podem aceitar, como estagiários, pelo prazo máximo de vinte e quatro meses, alunos regularmente matriculados e que venham frequentando, efetivamente, cursos de educação superior, de ensino médio, de educação profissional de nível médio ou de educação especial, vinculados à estrutura do ensino público e particular, oficiais ou reconhecidos.

- $\S 1^{\circ} 0$ estágio, sob-responsabilidade e coordenação da instituição de ensino e controlado pela unidade de recursos humanos do órgão ou entidade solicitante, será planejado, executado, acompanhado e avaliado em conformidade com os currículos e deverá propiciar complementação de ensino e aprendizagem aos estudantes, constituindose em instrumento de integração, de aperfeiçoamento técnico-cultural, científico e de relacionamento humano.

- $\S 2^{\circ}$ Somente poderão ser aceitos estudantes de cursos cujas áreas estejam relacionadas diretamente com as atividades, programas, planos e projetos desenvolvidos pelo órgão ou entidade nos quais se realizar o estágio.

Mas qual o entendimento sobre Portaria, segundo MENEZES (2007, p. 27) ${ }^{8}$, é um ato por meio do qual o titular do Órgão determina providências em caráter administrativo, com vistas a estabelecer normas referentes à organização, à ordem e ao funcionamento de serviço ou procedimentos para o próprio Órgão e/ou a outros Órgãos da Administração Pública, que da Administração Direta ou Indireta, assim como, norteia o cumprimento de dispositivos legais e disciplinares

E se tratando de Resoluções, que é o instrumento que se destina a disciplinar assunto de interesse interno, no caso desse estudo, emanado pelo Congresso Nacional, ou advindo pelo Conselho de Ministros. Ressalta-se que as resoluções não podem contrariar os regulamentos e os regimentos, mas explicá-los.

- A Resolução no 4/09, institui as Diretrizes Operacionais para o Atendimento Educacional Especializado na Educação Básica, modalidade Educação Especial.
- Por sua vez, as Diretrizes Curriculares Nacionais para a Formação de Professores da Educação Básica, em nível superior, curso de licenciatura, de graduação plena, são disciplinadas por meio da Resolução CNE/CP n $1 / 02$.

- As Diretrizes Nacionais para a educação de alunos que apresentem necessidades educacionais especiais, na Educação Básica, em todas as suas etapas e modalidades, são disciplinadas por meio da Resolução CNE/ CEB n $n^{\circ} / 01$.

- Em relação à duração e a carga horária dos cursos de licenciatura, de graduação plena, de formação de professores da Educação Básica em nível superior é disciplinado pela Resolução CNE/CP n $2 / 02$.

- O prazo de conclusão do curso de graduação, e a autorização para a concessão de dilatação de prazo de conclusão do curso de graduação aos alunos portadores de deficiência física, afecções congênitas ou adquiridas, é instrumento disciplinado pela Resolução no 02/81.

- E por fim, a Resolução n०05/87, altera a redação do Art. $1^{\circ}$ da Resolução $n^{\circ} 2 / 81$, do Conselho Federal de Educação, passando a vigorar $\mathrm{cm}$ a seguinte redação: "Ficam as Universidades e os Estabelecimentos Isolados de Ensino Superior autorizados a conceder dilatação do prazo máximo estabelecido para conclusão do curso de graduação, que estejam cursando, aos alunos portadores de deficiências físicas assim como afecções, que importem em limitação da capacidade de aprendizagem. Tal dilatação poderá ser igualmente concedida em casos de força maior, devidamente comprovados, a juízo da instituição".

Além desse conjunto de regulamentação há o AVISO CIRCULAR $n^{\circ}$ 277/96, dirigido aos Reitores das IES solicitando a execução adequada de uma política educacional dirigida aos portadores de necessidades especiais.

Por fim, e não menos relevante no entendimento do ator desse estudo, relata-se o ponto de vista sobre a coletânea de documentos em Nível Internacional que abordam a respeito da preocupação ao público assistido pelo olhar inclusivista: Convenção da ONU sobre os Direitos das Pessoas com Deficiência 


\section{Pode ser compreendida como uma mudança repentina em sentido institucional, e consiste: \\ FIM DO IGUAIS $X$ DIFERENTES $X$ NORMAIS $X$ DEFICIENTES.}

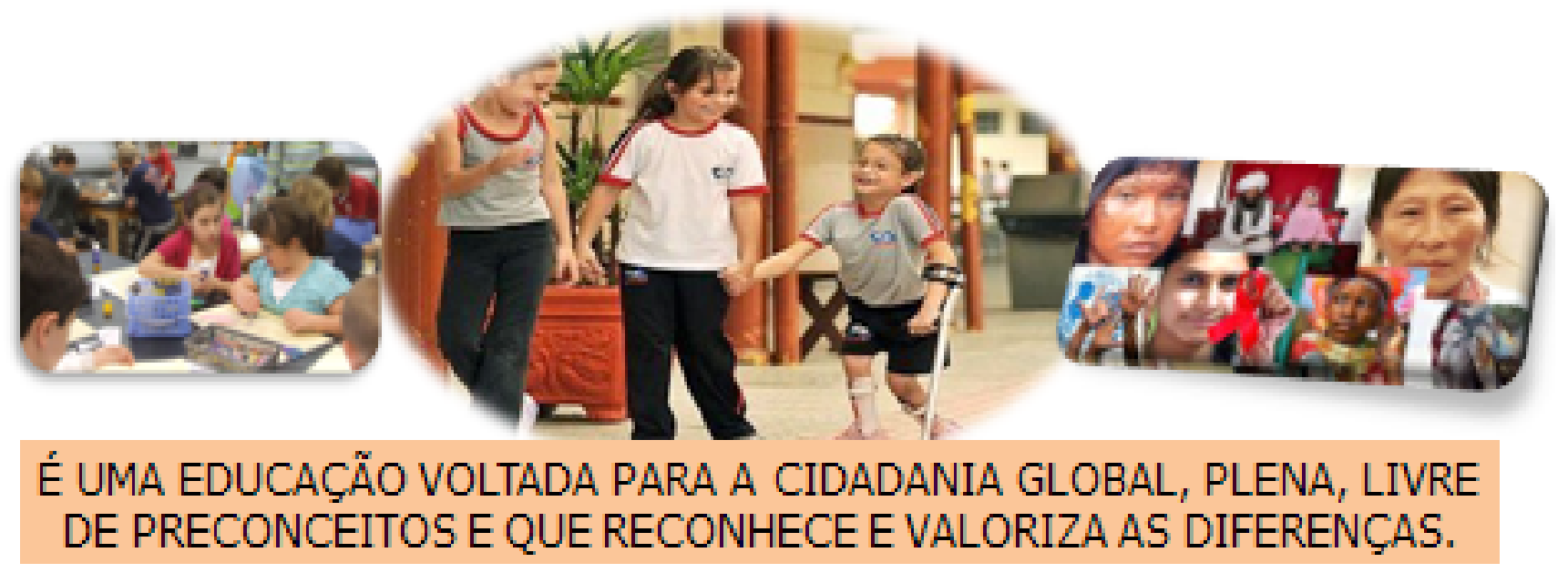

Figura 4 - Educação Inclusiva - "Iguais / Diferentes / Normais / Deficientes".

Fonte: http://educacaoinclusivaemfoco.com.br/os-beneficios-da-escola-

inclusiva/ (2017).

2007; Carta para o Terceiro Milênio; Declaração de Salamanca; Conferência Internacional do Trabalho; Convenção da Guatemala. Declaração dos Direitos das Pessoas Deficientes e Declaração Internacional de Montreal sobre Inclusão.

Esse conjunto de normatização e normalização estão contemplados pelo acervo documental da Secretaria de Educação Especial (Seesp) do Ministério de Educação, órgão destinado a desenvolver programas, projetos e ações a fim de implementar no Brasil a Política Nacional de Educação Especial, e que se destina aos alunos considerados públicoalvo da educação especial, sendo eles, aqueles com deficiência, transtornos globais de desenvolvimento e com altas habilidades/superdotação.

\section{III - MAS O QUE É EDUCAÇÃO INCLUSIVA?}

Para o autor desse artigo, Educação Inclusiva pode ser entendida como uma modalidade de ensino que tem como objetivo garantir o direito de todos à educação, isto é, igualdade de oportunidades e de valorização das diferenças humanas, abrangendo desta maneira as diversidades étnicas; sociais; culturais; intelectuais; físicas; sensoriais; e, de gênero dos seres humanos, conforme se evidencia na figura 4.

Considerando que a Educação Especial é destinada a atendimento "pessoas com alguma deficiência", e por outro lado a Educação Inclusiva direciona suas ações a garantir a educação para todos. Desta maneira, as figuras 05 e 06, a seguir, abordam tipologicamente a diferenciação entre Educação Especial e Educação Inclusiva.

A figura 05 é intitulada: Educação Especial "modalidade transversal a todos os níveis". Por sua vez, a figura 06: Educação Inclusiva "direitos iguais a todos e a todas no seio escolar".

\section{IV - CONSIDERAÇÕES FINAIS}

Nessa direção, como parte importante do pensar sobre Educação Inclusiva, é necessário refletir acerca do artigo $1^{\circ}$ da $\angle D B E N N^{\circ}$ 9.394/1996, que afirma que a educação abrange os processos formativos que se desenvolvem na vida familiar, na convivência humana, no trabalho, nas instituições de ensino e pesquisa, nos movimentos sociais e organizações da sociedade civil e nas manifestações culturais. Este conjunto de intenções é direcionado a disciplinar a educação no âmbito escolar. Mas, a educação escolar deverá vincular-se ao mundo do trabalho e à prática social. $O$ artigo analisa o conteúdo inserido no art. 58/LDBEN, que classifica Educação Especial: [como modalidade de educação escolar, oferecida, preferencialmente, na rede regular de ensino, para educando portadores de necessidades especiais]. 
Mas, há diferença entre Educação Especial e Educação Inclusiva?

Educação especial é uma modalidade de ensino que visa promover 0 desenvolvimento das potencialidades de pessoas portadoras de necessidades especiais, condutas típicas ou altas habilidades, e que abrange os diferentes niveis e graus do sistema de ensino.

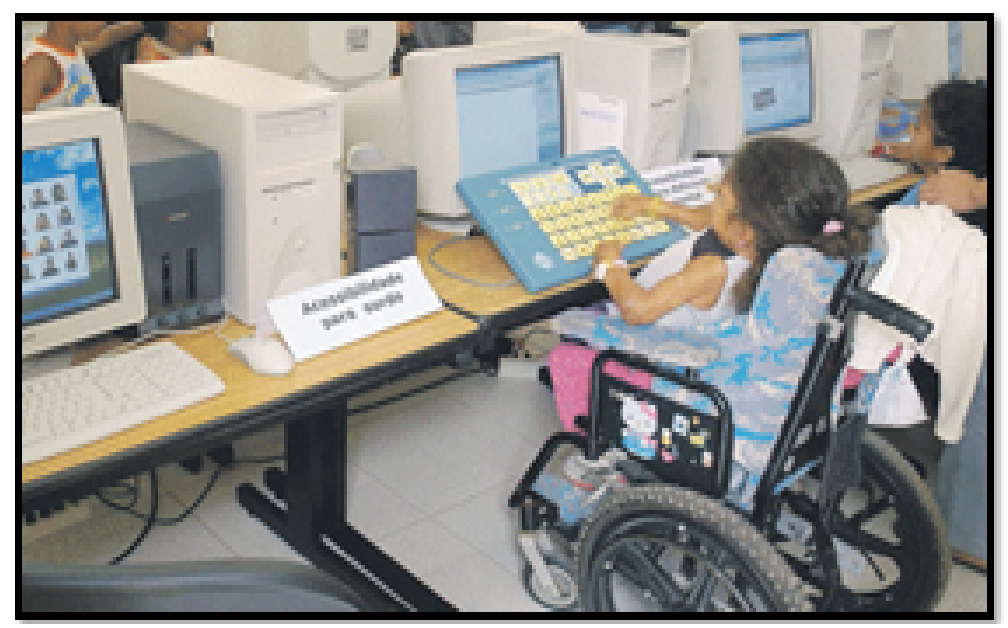

Figura 5 - Educação Especial - "modalidade transversal a todos os níveis". Fonte: http://educacaoinclusivaemfoco.com.br/os-beneficios-da-escola-inclusiva/ (2017).

Mas, há diferença entre Educação Especial e Educação Inclusiva?

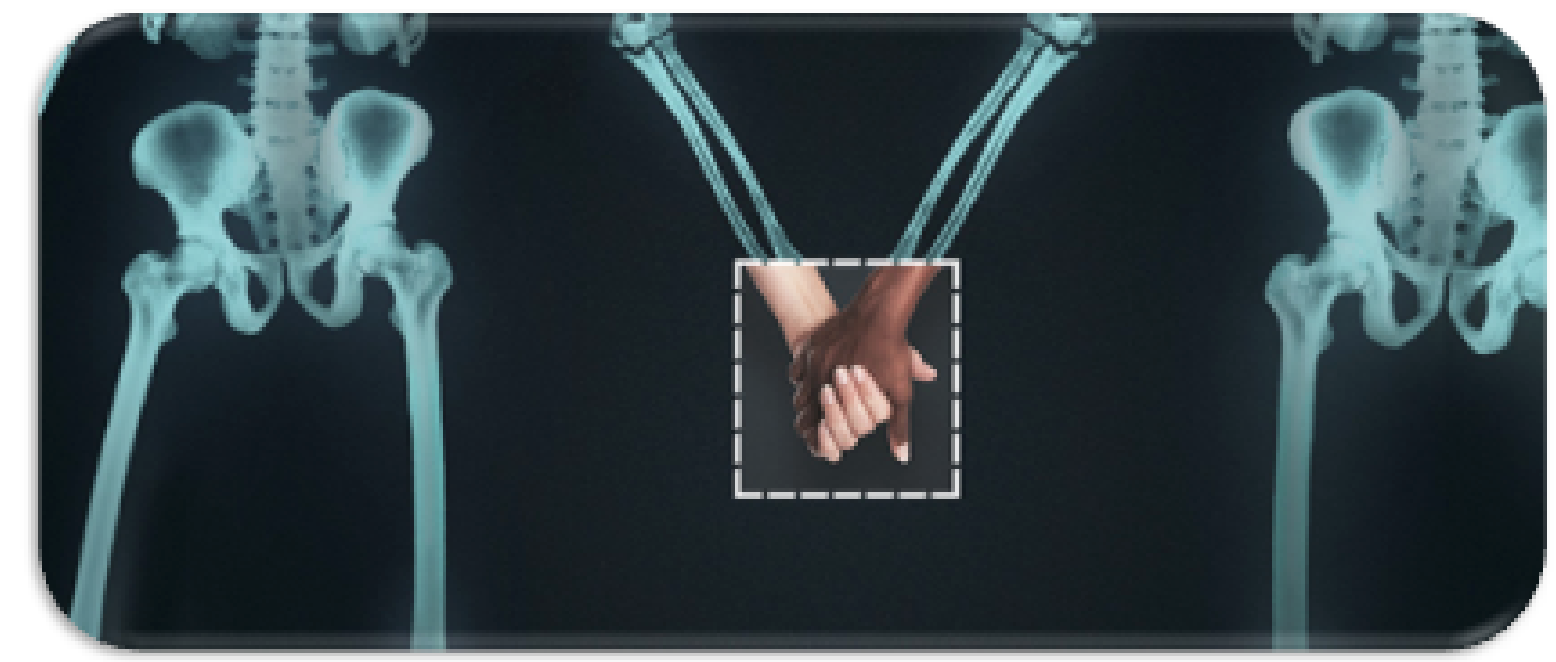

A EDUCAÇÃO INCLUSIVA APONTA PARA A TRANSFORMAÇÃO DE UMA SOCIEDADE INCLUSIVA, É UM PROCESSO EM QUE SE AMPLIA A PARTICIPAÇẪO DE TODOS NOS ESTABELECIMENTOS DE ENSINO REGULAR.

Figura 6 - Educação Inclusiva - "direitos iguais a todos e a todas no seio escolar". Fonte: http://educacaoinclusivaemfoco.com.br/os-beneficios-da-escola-inclusiva/ (2017). 
Para o autor deste artigo, a "Educação Inclusiva, vai muito além do pensar aos portadores de necessidades especiais". "É um processo de inclusão social"... "De equidade social"... "É um dever em um país de Estado Democrático de Direito".

\section{NOTAS}

01. A síndrome de Down é causada pela presença de três cromossomos 21 em todas ou na maior parte das células de um indivíduo. Isso ocorre na hora da concepção de uma criança. As pessoas com síndrome de Down, ou trissomia do cromossomo 21, têm 47 cromossomos em suas células em vez de 46, como a maior parte da população.

02. É uma sociedade civil, filantrópica, de caráter cultural, assistencial e educacional. o objetivo maior desta entidade é melhorar as condições de vida do portador de deficiência, e, principalmente, assegurar-lhe o desenvolvimento e os direitos de cidadão.

03. É um transtorno neurológico caracterizado por comprometimento da interação social, comunicação verbal e não verbal e comportamento restrito e repetitivo.

04. É um conceito que se refere a um Estado em que existe o respeito pelos direitos humanos e pelas e garantias fundamentais. Deve existir a garantia dos direitos individuais e coletivos, dos direitos sociais e dos direitos políticos.

05. BRASIL. Lei de Diretrizes e Bases da Educação Nacional. Lei $n^{\circ} 4.024$, de 20 de dezembro de 1961. Estabelece as diretrizes e bases da educação nacional. Brasília, DF, 1961.

06. Brasil. Constituição (1988, p. 123 - Da Ordem Social).

07. Joaquim Augusto Souza de Menezes. Negócios Públicos II. Belém - Pará. Universidade da Amazônia. EAD. 2007.

\section{REFERENCIAL BIBLIOGRÁFICO}

BRASIL. Ministério da Educação. Publicações $\mathrm{MEC} /$ Secretaria de Educação Especial/Legislação Específica/Documentos Internacionais. Disponível: http://portal.mec.gov.br/secretaria-de- educacao-especial-sp-598129159/legislacao. Acesso (Agosto a Dezembro de 2017).

ILUSTRAÇÕES. Disponíveis em: http:// educacaoinclusivaemfoco.com.br/osbeneficios-da-escola-inclusiva/. Acesso (Agosto a Dezembro de 2017). E copilados em formato de slides pelo autor deste artigo.

MEIRELLES, Hely Lopes. Direito Administrativo

Brasileiro. Malheiros, São Paulo, 2003.

MENEZES, Joaquim Augusto Souza. Negócios

Públicos II. Belém - Pará. Universidade da Amazônia. EAD. 2007.

MENEZES, Joaquim Augusto Souza. Acervo fotográfico de família. 2017.

\section{SOBRE O AUTOR}

Joaquim Augusto Souza de Menezes é Administrador/Professor/Autor de obras acadêmicas/Produtor Cultural. Doutorando em Artes/UFPA. Mestre em Gestão e Desenvolvimento Regional pela Universidade de Taubaté/SP. Pós-graduado em Elaboração e Análise de Projetos Econômicos, Marketing e Gestão Governamental. 